\title{
INOCULAÇÃO, BIOATIVAÇÃO E ADUBAÇÃO NITROGENADA EM COBERTURA PARA MILHO SEGUNDA SAFRA: DESENVOLVIMENTO E PRODUTIVIDADE
}

\author{
CORDEIRO JUNIOR, Paulo Sérgio ${ }^{1}$; SANTOS, Guilherme Xavier Lúcio dos ${ }^{2}$; FECCHI, Angela \\ Cristina Bieras ${ }^{3}$; BÁRBARO-TORNELI, Ivana Marino ${ }^{4}$; CORREIA, Alessandra Neves ${ }^{2}$; FINOTO, \\ Everton Luis ${ }^{5}$; DONÁ, Sérgio ${ }^{6}$; NAKAYAMA, Fernando Takayuki ${ }^{7}$
}

ISSUE DOI: $10.3738 / 1982.2278 .3624$

\begin{abstract}
RESUMO: O milho apresenta grande demanda de nitrogênio, sendo interessante a busca de alternativas de maior sustentabilidade econômica e ambiental. O objetivo do presente estudo foi avaliar o efeito da aplicação de inoculante para gramíneas, em combinação com um bioativador de plantas, na presença e ausência do nitrogênio em cobertura, nos parâmetros agronômicos de desenvolvimento e na produtividade do milho segunda safra. O experimento foi conduzido na APTA Regional, Polo Centro Norte, em Pindorama, SP. O experimento foi implantado seguindo esquema fatorial completo 4 × 2, sendo considerado como primeiro fator as diferentes condições de tratamentos de semente: ausência de inoculante e bioativador (controle-T1); apenas inoculante a base de Azospirillum brasilense (T2); apenas bioativador (T3); combinação entre inoculante A. brasilense e bioativador (T4) e como segundo fator: a presença e ausência de adubação nitrogenada em cobertura. Estes tratamentos foram distribuídos seguindo delineamento em blocos casualizados, com quatro repetições. Foram realizadas leituras correspondentes ao teor de clorofila na folha, indicando a saúde das plantas em virtude dos tratamentos submetidos. Para determinação do desenvolvimento das plantas, realizou-se medições de altura da planta e de inserção de espiga, diâmetro (a e b) e comprimento do entre nó logo abaixo espiga. Na sequência foi determinado o número de fileira de grãos e número de grãos na fileira, peso de 100 grãos e a produtividade. Como resultados, destacou-se a combinação de inoculante $A$. brasilense e bioativador nas sementes, obtendo maiores resultados tanto no crescimento/desenvolvimento da planta quanto na produtividade, sobretudo na presença de nitrogênio em cobertura.
\end{abstract}

Palavras-chave: Azospirillum brasilense. Bioativador de plantas, Milho safrinha.

\section{INOCULATION, BIOATIVATION AND NITROGEN FERTILIZATION IN SECOND SAFRA CORN COVERAGE: DEVELOPMENT AND PRODUCTIVITY}

\footnotetext{
SUMMARY: Maize has a great demand for nitrogen, and it is interesting to search for alternatives of greater economic and environmental sustainability. The objective of the present study was to evaluate the effect of inoculant application for grasses, in combination with a plant bioactivator, in the presence and absence of nitrogen in coverage, in the agronomic parameters of maize development and productivity Second crop. The experiment was carried out at APTA Regional, Polo Centro Norte, in Pindorama, SP. The experiment was implemented following a 4 x 2 complete factorial scheme, being considered as the first factor the different conditions of seed treatments: absence of Inoculant and Bioactivator (Control-T1); Only inoculant the base of Azospirillum brasilense (T2); Only Bioactivator (T3); Combination between Inoculant with A. Brasilense and Bioactivator (T4) and as the second factor: the presence and absence of nitrogen fertilization in coverage. These treatments were distributed according to a randomized block design, with four replications. Readings corresponding to the chlorophyll content in the leaf were performed, indicating the health of the plants due to the treatments submitted. In order to determine the plant development, measurements were made of height of the plants and insertion of the ear, diameter (A and B) and length of the between knot just below the spike. In sequence, the number of grain row and number of grains in the row, weight of

${ }^{1}$ Mestrando em Produção Vegetal - FCAV-UNESP, Jaboticabal, SP;

${ }^{2}$ Engenheiro(a) Agrônomo(a), Bolsista de Aperfeiçoamento Técnico FUNDAG/APTA/SAA - PRDTA Centro Norte - Pindorama, SP;

${ }^{3}$ Professora, Dra. - Centro Universitário de Rio Preto-UNIRP, São José do Rio Preto, SP;

${ }^{4}$ Pesquisadora Cientifica, Dra. - PRDTA Alta Mogiana, Colina, SP;

${ }^{5}$ Pesquisador Cientifico, Dr. - PRDTA Centro Norte, Pindorama, SP;

${ }^{6}$ Pesquisador Cientifico, Msc - PRDTA Médio Paranapanema, Assis, SP;

${ }^{7}$ Pesquisador Cientifico, Dr. - PRDTA Alta Paulista - Adamantina, SP.
} 
100 grains and grain yield were determined. As results, we highlighted the combination of Inoculant with $A$. Brasilense and Bioactivator in seeds, obtaining higher results both in plant growth/development and grains yield, especially in the presence of nitrogen in coverage.

Keywords: Azospirillum brasilense. Plant bioactivator. Safflowed maize.

\section{INTRODUÇÃO}

O milho (Zea mays L.) é um dos principais cereais cultivados no mundo, sendo que fatores como a fertilidade do solo e o nível tecnológico adotado no uso de insumos afetam diretamente a produção (GUIMARÃES, 2007). Na Região Centro-Oeste Brasileira, principal produtora nacional, a área plantada está estimada em 7.122,4 mil hectares, representando um incremento de 5,6\% em relação ao plantio passado, com uma estimativa de produção de 59,67 milhões de toneladas cultivadas em 11,25 milhões de hectares (CONAB, 2017). O cultivo de milho na segunda safra tem sido viável economicamente para os produtores. Além do retorno financeiro, a segunda safra com milho proporciona os benefícios agronômicos do princípio da rotação de culturas.

Devido ao alto custo dos fertilizantes industrializados e a uma conscientização em prol de uma agricultura sustentável e menos poluente, existe um interesse crescente pelo uso de inoculantes contendo bactérias promotoras de crescimento de plantas (BPCP), as quais incrementam positivamente na produtividade (HUERGO et al., 2008). Para o sucesso da inoculação destas bactérias, é importante a escolha de genótipos adaptados às condições locais e propensos à colonização, além da concentração de microrganismos no inoculante e a forma de aplicação do mesmo também pode interferir na resposta dessas bactérias benéficas (MOREIRA; SIQUEIRA, 2006).

As Bactérias Promotoras do Crescimento de Plantas (BPCP) como o Azospirillum brasilense, denominadas diazotróficas ou fixadoras de $\mathrm{N}_{2}$, aportam nitrogênio às plantas via fixação biológica (FBN) e aumentam a eficiência de utilização dos fertilizantes. Associam-se em diferentes graus de especificidade às espécies da família Poaceae, como ocorre com o milho, representando uma estratégia viável economicamente para essa cultura, além dos benefícios ambientais associados à redução parcial ou total do uso de fertilizantes, principalmente os nitrogenados (HUNGRIA et al., 2015). Entre os efeitos positivos, da interação entre Azospirillum e milho estão o aumento da produção de matéria seca e grãos, e também o maior acúmulo de nitrogênio nas plantas (HUNGRIA et al., 2010).

A utilização de substâncias, tais como os bioativadores, aumentam o nível de importância do conhecimento em determinadas culturas, como no milho segunda safra, na medida em que existe um aumento no potencial genético dos híbridos modernos e a presença de fatores limitantes de características edafoclimáticas regional. Os bioativadores têm mostrado influência em muitos processos metabólicos nas plantas, tais como: respiração, fotossíntese, síntese de ácidos nucléicos e absorção de íons, objetivando o incremento na produtividade em função de processos ligados ao enraizamento, desenvolvimento vegetativo, floração, frutificação, senescência, amenização dos efeitos de estresses bióticos e abióticos que comprometem diretamente na sucesso cultura do milho. Segundo Ferreira et al. (2007) os bioativadores são obtidos pela mistura de dois ou mais reguladores vegetais, com outras substâncias (aminoácidos, nutrientes, vitaminas), que promovem o equilíbrio hormonal das plantas e favorecem a expressão do potencial genético do material.

Para a obtenção de elevadas produtividades, o milho necessita ter suas exigências nutricionais plenamente satisfeitas, de forma a atender a grande demanda de extração de nutrientes do solo, sobretudo de N, que, além de ser o nutriente extraído em maior quantidade, é o que tem a recomendação de adubação e o manejo mais complexos, tendo a necessidade de ter sua aplicação de forma parcelada 
(CANTARELlA E DUARTE, 2004). Resultados de vários experimentos conduzidos no Brasil, sob diversas condições de clima, solo e sistemas de cultivo, mostram resposta generalizada da cultura à adubação nitrogenada (EMBRAPA, 2011).

A agricultura está em constante processo de geração de novos conhecimentos, buscando, através da pesquisa, conhecer as causas dos efeitos do uso de diferentes substâncias para a obtenção de maior eficiência na produção agrícola. O desenvolvimento e a produtividade das culturas são controladas, além de fatores genéticos e ambientais ou tratos culturais, por fatores fisiológicos e hormonais. Além dos macro e micronutrientes essenciais para o ciclo da cultura, o uso de bioativadores e inoculantes, usado nas culturas agrícolas, tem-se intensificado, obtendo resultados importantes nas lavouras do Brasil, o que gera uma necessidade de se conhecer, com maior detalhe, o funcionamento desses insumos químicos e biológicos em combinação com demais tecnologias, como a adubação nitrogenada em híbridos modernos de milho.

No entanto, pouca informação existe sobre o efeito dessas combinações entre inoculante + bioativador, na presença e ausência da adubação nitrogenada em cobertura, sobre a qualidade das plantas e a produtividade do milho safrinha. Dessa forma, devem-se avaliar os reais ganhos com a incorporação desses produtos no desenvolvimento e produção da cultura.

Neste contexto, o objetivo do presente estudo foi avaliar o efeito da aplicação de inoculante a base de Azospirillum brasilense, em combinação com Bioativador Nobrico Star, na presença e ausência do nitrogênio mineral em cobertura, nos parâmetros agronômicos de desenvolvimento e na produtividade do milho segunda safra.

\section{MATERIAL E MÉTODO}

O experimento foi conduzido na APTA Regional, Polo Centro Norte vinculado a Agência Paulista de Tecnologia do Agronegócio (APTA), pertencente à Secretaria da Agricultura e Abastecimento do Estado de São Paulo (SAA - SP), localizado no município de Pindorama, SP. A área experimental tem solo caracterizado como Argissolo Eutrófico Vermelho-Amarelo Abrupto (EMBRAPA, 2013), considerado profundo, com horizonte $\mathrm{A}$ arenoso e horizonte $\mathrm{B}$ textural com alta fertilidade e topografia plana. Conforme classificação de Koppen, o clima enquadra-se no tipo Aw, definido como tropical úmido com estação chuvosa no verão e seca no inverno.

Em um talhão onde foi cultivado amendoim (Arachis hypogaea) na safra de verão, realizou-se a implantação do experimento. O resultado da análise química do solo está exposto na tabela 1. O hibrido de milho utilizado no presente trabalho foi o AS 1633, com tecnologia VT PRO ${ }^{\mathrm{TM}}$, de ciclo precoce, com

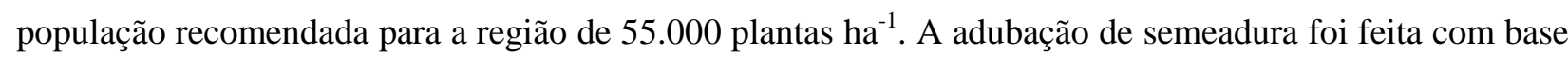
nas recomendações do Boletim Técnico No100 (RAIJ et al., 1997), sendo fornecido $280 \mathrm{~kg} \mathrm{ha}^{-1}$ da formula 08 - 28 - 16. Para a implantação do experimento, utilizou-se conjunto semeadura adubadora Jumil, modelo pneumática, de 4 linhas espaçadas a 0,90 metros, equipada com haste descompactadora no sistema de distribuição de adubos e trator de 95 cv's 4 x 2 TDA. 
Tabela 1. Resultado da análise química do solo no local de execução do experimento de milho segunda safra, Pindorama, SP, 2017.

\begin{tabular}{lccccccccc}
\hline $\begin{array}{l}\text { Profundidade } \\
(\mathbf{m})\end{array}$ & $\begin{array}{c}\mathbf{p H} \\
\left(\mathbf{C a C l}_{2}\right)\end{array}$ & $\mathbf{P}$ & $\begin{array}{c}\mathbf{S O 4}^{2-} \\
\mathbf{m g ~ d m}^{-3}\end{array}$ & $\mathbf{K}^{+}$ & $\mathbf{C a}^{2+}$ & $\begin{array}{c}\mathbf{M g}^{2+} \\
\mathbf{m m o l c ~ d m}^{-3}\end{array}$ & $\mathbf{A l}^{3+}$ & $\mathbf{H + A l}$ & $\mathbf{V}$ \\
$0-0,20$ & 5,7 & 20 & 8 & 2,5 & 29 & 21 & 0 & 15 & 77,8 \\
$0,20-0,40$ & 5,6 & 25 & 10 & 2,4 & 22 & 20 & 0 & 17 & 62 \\
\hline
\end{tabular}

O experimento seguiu o esquema fatorial completo $4 \times 2$, sendo considerado como primeiro fator: as diferentes condições de tratamentos de semente: sem inoculante a base de bactérias do gênero Azospirillum brasilense e sem Bioativador (controle-T1); apenas com inoculante a base de Azospirillum brasilense (T2); apenas Bioativador (T3); combinação entre inoculante contendo Azospirillum brasilense e Bioativador (T4) e como segundo fator: presença e ausência de adubação nitrogenada em cobertura. Esses tratamentos foram distribuídos seguindo delineamento em blocos casualizados, com quatro repetições. O inoculante comercial utilizado como fonte da bactéria foi o Biomax Premium ${ }^{\circledR}$ e o bioativador comercial foi o Nobrico Star®, composto por extrato de algas, aminoácidos, polissacarídeos e ácidos orgânicos (húmicos e fúlvicos) (Garantias do produto: Carbono Orgânico Total $=14 \%$; Alfa L- aminoácidos livres $=$ $6 \%$; Extrato de algas $=3 \%$; Molibdênio solúvel em água $=2 \%$; Polissacarídeos $=5 \%$ ), na dosagem de $150 \mathrm{~mL} / 20 \mathrm{Kg}$ e $68 \mathrm{~mL} / 20 \mathrm{Kg}$ respectivamente.

Para a aplicação do nitrogênio mineral em cobertura, utilizou-se como fonte a uréia, na dosagem de $100 \mathrm{~kg} \mathrm{ha}^{-1}$, sendo esta dose dividida em duas aplicações (estádios V4 e V6), apenas nas parcelas com a presença do nutriente, como sugerido por Fancelli e Dourado Neto (2000), em que o ideal para a aplicação de nitrogênio em cobertura na cultura de milho seja efetuada quando as plantas apresentarem 4 folhas plenamente desenvolvidas, para que os elementos estejam plenamente disponíveis para a planta a partir da emissão da quinta folha, fase a partir da qual os nutrientes devem estar prontamente disponíveis para que a produtividade não seja afetada.

A aplicação do adubo foi realizada nas proximidades da linha de semeadura, por meio da adubabora de cobertura para milho Tatu Marchesan ${ }^{\circledR}$, cumprindo a função de depositar o adubo na camada de $5-10 \mathrm{~cm}$ de profundidade visando maior eficiência de aproveitamento.

As unidades experimentais ou parcelas foram compostas por parcelas com $36 \mathrm{~m}^{2}$ (4 linhas com 10 metros de comprimento espaçadas a 0,90 metros entre si). Como área útil foram desconsiderados $31,5 \mathrm{~m}^{2}$ correspondente a exclusão de 2,5 metros nas extremidades e 2 linhas.

Foram realizadas 3 determinações ou leituras correspondente ao teor de clorofila na folha, avaliada com o clorofilômetro modelo Minolta SPAD-502 (Soil Plant Analysis Development) nos estádios V3, V6 e no espigamento, utilizando 10 plantas da área útil da parcela e 5 folhas para extração da média. Nos estádios vegetativos, as leituras com o medidor foram feitas na $3^{\mathrm{a}}$ e $6^{\mathrm{a}}$ folha totalmente expandidas e no espigamento as leituras foram feitas na folha-índice (primeira abaixo da espiga). As leituras no medidor de clorofila ( 3 por folha) foram realizadas em pontos situados na metade a 2/3 do comprimento da folhas, apartir da base e a $2 \mathrm{~cm}$ de umas das margens da folha. Alguns pesquisadores evidenciaram a relação entre a leitura do clorofilômetro e teor de clorofila na folha (MARQUAD e TIPTON, 1987) e entre teor de clorofila na folha e teor de $\mathrm{N}$ na planta (ARGENTA et al., 2001a).

No estádio de grão leitoso, foram realizadas as medições de altura de plantas, altura de inserção da primeira, diâmetro (a e b) e comprimento do entre nó logo abaixo da primeira espiga em centímetros. Os dados foram coletados em 10 plantas da área útil da parcela utilizando régua e paquímetro. 
Por ocasião da colheita, foram colhidas todas as espigas da área útil da parcela, de forma separada e identificas, onde foram retiradas 10 espigas para determinação do número de fileira de grãos e número de grãos na fileira. Logo após, as espigas foram trilhadas e os grãos foram pesados corrigindo o teor de umidade para $13 \%$, em seguida, foi determinado o peso de 100 grãos e a produtividade final em $\mathrm{kg} \mathrm{ha}^{-1}$.

Para homogeneização de todos os tratamentos com adubações de cobertura equivalentes em termos de potássio, todas as parcelas receberam $65 \mathrm{~kg} \mathrm{ha}^{-1}$ de cloreto de potássio no estádio V4 (DUARTE, 2015b). A aplicação do adubo foi realizada a lanço, em área total, por meio da esparramadeira modelo Vicon ${ }^{\circledR}$.

Para o controle de pragas, foram efetuadas duas aplicações (estádio V6 e V8) dos inseticidas Engeo $^{\mathrm{TM}}$ Pleno + Fastac $100 \mathrm{SC}$, na dosagem $0,25 \mathrm{~L} \mathrm{ha}^{-1}$ e $0,2 \mathrm{~L} \mathrm{ha}^{-1}$ respectivamente, utilizando pulverizador tratorizado de barras devidamente calibrado para a vazão de $300 \mathrm{~L} \mathrm{ha}^{-1}$, com pontas duplo leque e ângulo de deposição de $110^{\circ} \mathrm{com}$ a barra de pulverização a $50 \mathrm{~cm}$ da superfície do solo.

Os dados obtidos foram submetidos a análise de variância sendo a comparação de médias pelo teste de Tukey a 5\% de probabilidade e análise de correlação entre, leitura do teor de clorofila na folha, características agronômicas, componentes básicos de produção e produtividade.

As condições climáticas ao longo da execução do experimento para o município de Pindorama, SP, estão exposta na Figura 1.

Figura 1. Precipitação $(\mathrm{mm})$, temperatura máxima e mínima $\left({ }^{\circ} \mathrm{C}\right)$ ao longo da execução o experimento, milho segunda safra 2017, município de Pindorama, região Norte do Estado de São Paulo. Fonte, Centro Integrado de Informações Agrometeorológicas (CIIAGRO).

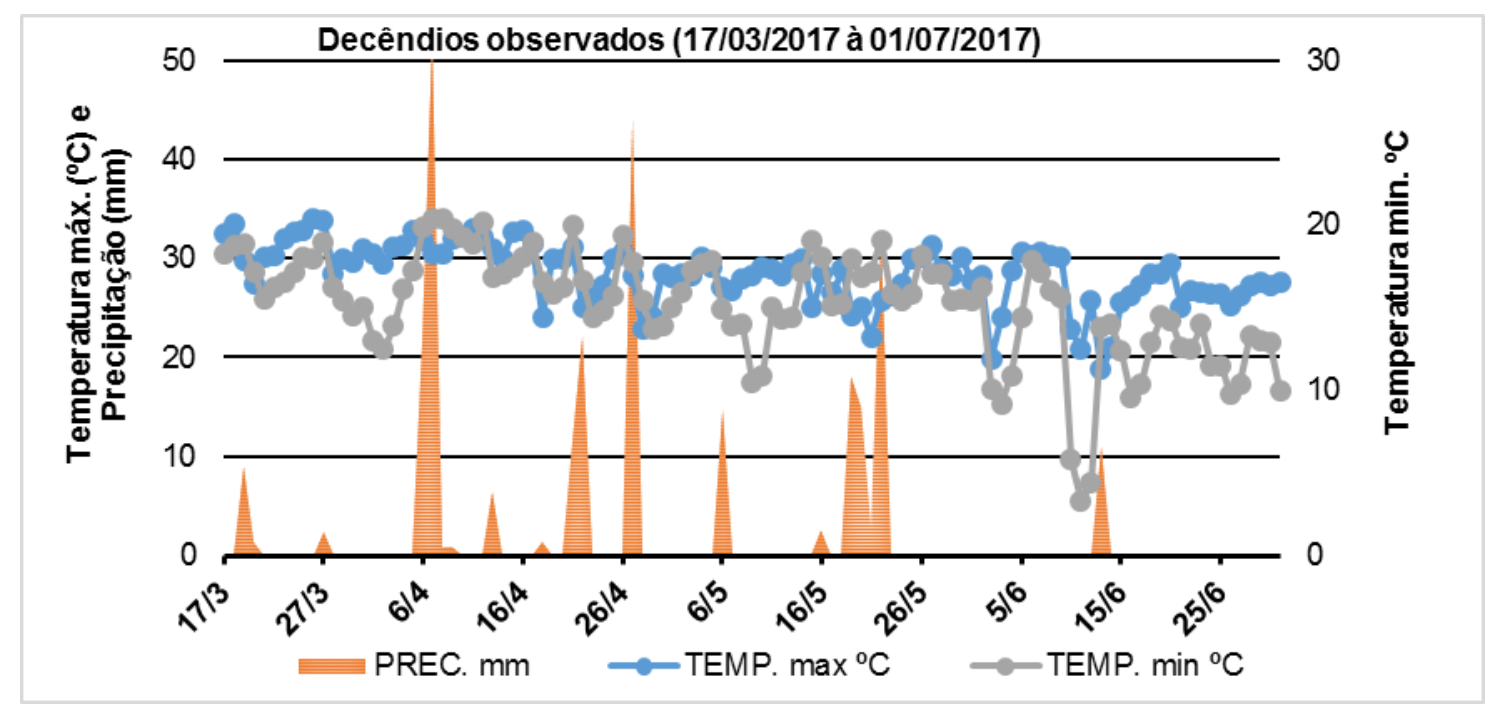

\section{RESULTADO E DISCUSSÃO}

Os dados obtidos demonstram haver diferença significativa entre os tratamentos de aplicação do inoculante e bioativador de forma independe e também na interação entre ambos.

No estádio de três folhas de milho completamente desenvolvidas, os valores de leitura obtidos no clorofilômetro estiveram abaixo dos considerados adequados para todos os tratamentos estudados (tabela 2). Este resultado indica que a dose de $\mathrm{N}$ aplicada na semeadura $\left(22,4 \mathrm{~kg}_{\text {.ha }}{ }^{-1}\right)$ não foi suficiente para suprir as necessidades das plantas até esses estádios. Possivelmente, tal fato pode ser explicado pela ação de microrganismos que atuam na decomposição do material orgânico que por sua vez necessitam assimilar 
nitrogênio do sistema solo (VICTORIA et al., 1992). Apesar do baixo nível de $\mathrm{N}$ nas plantas, os resultados

da primeira leitura SPAD demonstraram haver diferença significa entre os tratamentos de sementes, destacando-se a combinação entre inoculante + bioativador e o uso do nitrogênio em cobertura.

De acordo com ARGENTA et al. 2001, determinando o nível de $\mathrm{N}$ na planta de milho para diagnóstico, as leituras no clorofilômetro acima de 38,4 no estádio V3, 42,1 no estádio V6 e 45,9 no espigamento, representam nível adequado de $\mathrm{N}$ na planta.

Tabela 2. Leitura do clorofilômetro (Leitura SPAD) nos estádios V3, V6 e espigamento do milho (E), considerando a utilização de inoculante e bioativador via semente e a presença e ausência do nitrogênio em cobertura, em experimento conduzido na segunda safra, Pindorama, SP, 2017.

\begin{tabular}{lrrr}
\hline $\begin{array}{l}\text { Tratamento de } \\
\text { sementes (TS) }\end{array}$ & SPAD V3 & SPAD V6 & SPAD E \\
\hline Controle & $29,73 \mathrm{c}$ & & \\
Inoculação & $33,20 \mathrm{~b}$ & $42,90 \mathrm{c}$ & $42,30 \mathrm{c}$ \\
Bioativação & $33,40 \mathrm{ab}$ & $45,46 \mathrm{~b}$ & $46,57 \mathrm{~b}$ \\
Inoculação +Bioativação & $37,39 \mathrm{a}$ & $45,11 \mathrm{~b}$ & $47,11 \mathrm{~b}$ \\
\hline Teste F & $129,48^{* *}$ & $48,31 \mathrm{a}$ & $49,75 \mathrm{ab}$ \\
\hline Cobertura (C) & $32,10 \mathrm{~b}$ & $92,99 * *$ & $218,19 * *$ \\
Sem N & $34,75 \mathrm{a}$ & $44,68 \mathrm{~b}$ & $45,15 \mathrm{~b}$ \\
Com N & $92,94 * *$ & $46,21 \mathrm{a}$ & $47,71 \mathrm{a}$ \\
\hline Teste F & & $44,17 * *$ & $151,20 * *$ \\
\hline Interação & $0,66 \mathrm{~ns}$ & & \\
TS x C & 8,32 & 11,43 & $9,45 \mathrm{~ns}$ \\
CV (\%) & & & \\
\hline
\end{tabular}

Médias seguidas pela mesma letra minúscula na coluna, não diferem entre si pelo teste de Tukey a $5 \%$ de probabilidade. $n s=$ não significativo. $* *=$ significativo a $5 \%$.

Sendo o nitrogênio um componente estrutural da molécula de clorofila, dados que demonstram o teor de clorofila nas folhas, são utilizados para inferir a concentração de nitrogênio nestes órgãos.

No estádio de seis folhas, houve resposta significativa entre os tratamentos de sementes e a presença e ausência do nitrogênio em cobertura, em que todos os tratamentos estudados foram superiores aos níveis considerados adequados para a cultura do milho (tabela 2), demonstrando o efeito da interação entre o uso de inoculante e bioativador associado ao nitrogênio mineral (tabela 3). Também é possível notar que ambos os tratamentos inoculante e bioativador, aplicados isoladamente, não diferiram estatisticamente um do outro. 
Tabela 3. Desdobramento da interação entre os tratamentos de sementes e a presença e ausência do nitrogênio em cobertura para a leitura SPAD no espigamento do milho conduzido na segunda safra, Pindorama, SP, 2017.

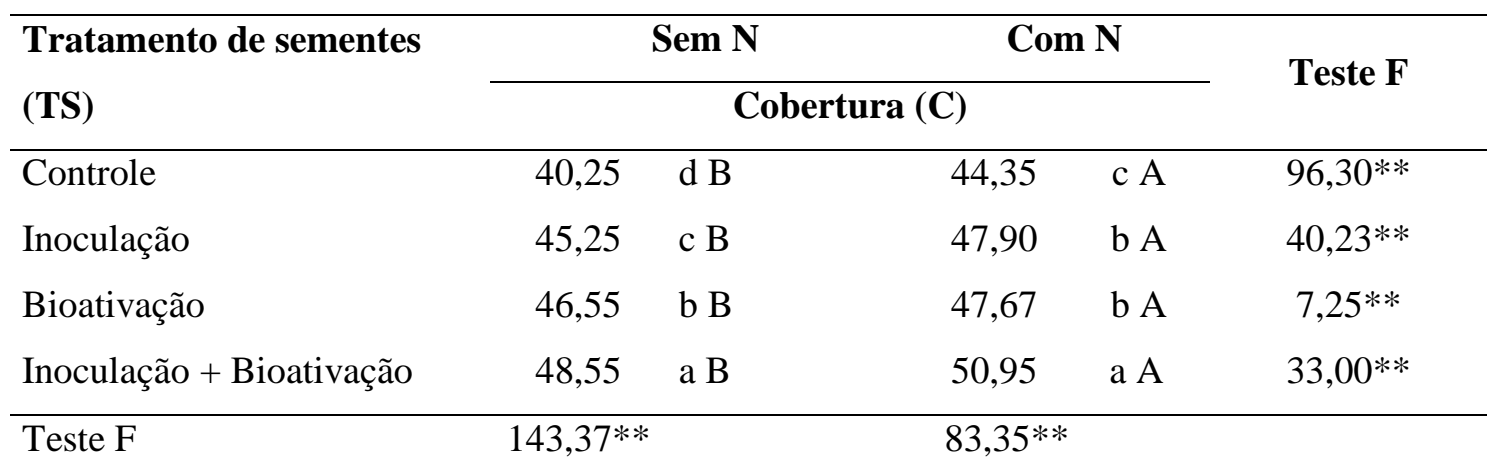

Médias seguidas pela mesma letra maiúscula na linha e minúscula na coluna, não diferem entre si pelo teste de Tukey a $5 \%$ de probabilidade. $n s$ = não significativo. $* *$ = significativo a $5 \%$.

No estádio de espigamento, os valores de leitura do clorofilômetro foram superiores para os tratamentos contendo inoculante, bioativador e inoculante+bioativador na presença do nitrogênio em cobertura. Tais resultados refletem o nível suficiente de $\mathrm{N}$ nas plantas, ou seja, apenas o tratamento controle requeriam a suplementação de adubação nitrogenada, mostrando a eficiência positiva dos insumos biológicos (inoculante e bioativador). RAJCAN e TOLLENAAR, 1990, verificaram que 60\% do $\mathrm{N}$ presente nos grãos de milho, foram absorvidos após o espigamento, tendo continuidade de absorção de $\mathrm{N}$ durante o período de enchimento de grãos, implicando menor remobilização deste nutriente de órgãos vegetativos, resultando em aumento da duração da área foliar e prolongamento do período de acúmulo de matéria seca. Estas duas características são importantes, pois estão associadas a altos rendimentos de grãos de milho (MOLL et al., 1994).

O aumento da biomassa vegetal apresenta uma estreita relação com o suprimento de nitrogênio. A energia e estrutura molecular necessárias para a incorporação do nitrogênio são supridas pelo metabolismo dos carboidratos, o qual, por sua vez, depende da fotossíntese. Fechando o ciclo da interdependência metabólica, a fotossíntese depende de compostos contendo nitrogênio, como por exemplo, a clorofila (LARCHER, 2004).

Quanto as características agronômicas, foram observadas diferenças significativas para todas as variáveis analisadas, sendo constatada a interação entre os fatores tratamento de sementes com a cobertura. Destaca-se com valores superiores a combinação de inoculante+bioativador para altura de planta, altura de inserção da primeira espiga, diâmetro do colmo e comprimento do entre nó (Tabela 4).

Estes resultados já eram esperados, uma vez que, o bioativador é precursor de auxina (hormônio de crescimento vegetal) e as bactérias aumentam a eficiência dos fertilizantes e amenizam o estresse hídrico, favorecendo o bom desenvolvimento das plantas de milho.

Dentre os benefícios de A. brasiliense destaca-se a produção de hormônios vegetais (ácido indolacético, giberilinas e citocininas), os quais estimulam o crescimento do sistema radicular de diversas espécies de plantas, contribuindo para uma maior absorção de água e nutrientes e maior tolerância a estresses como salinidade e seca. Estudos também relatam, para o gênero Azospirillum, a ligação com as seguintes respostas fisiológicas: melhoria em parâmetros fotossintéticos das folhas, incluindo teor de clorofila; maior elasticidade da parede celular; maior produção de biomassa; maior altura de plantas, dentre outros (HUNGRIA, 2011).

O bioativador utilizado neste experimento, possui o aminoácido triptofano em sua constituição, o qual é precursor do ácido indol-acético (CASTRO et al., 2005). 
O resultado expressivo apresentado pelo tratamento inoculante+bioativador, pode estar relacionado ao fato de ambos os tratamentos de semente aumentarem a concentração de auxina (ácido indol-acético) nas plantas, isso pode explicar, pelo menos em parte, o maior crescimento/desenvolvimento das plantas de milho que receberam este tratamento, independentemente da adubação de cobertura. A auxina está envolvida com o maior desenvolvimento do sistema radicular, aumento da divisão celular, alongação celular e melhor desenvolvimento dos grãos (TAIZ e ZEIGER, 2004).

Tabela 4. Características agronômicas, altura de planta (AP), altura de inserção da primeira espiga (AIE), diâmetro do colmo logo abaixo da primeira espiga (DC) e comprimento do entre nó logo abaixo a primeira espiga (CE) em centímetros do híbrido de milho AS 1633 VT PRO3 ${ }^{\mathrm{TM}}$ no estádio de grão leitoso, em função dos diferentes tipos de tratamento de sementes e a presença e ausência do nitrogênio em cobertura, conduzido na segunda safra, Pindorama, SP, 2017.

\begin{tabular}{|c|c|c|c|c|}
\hline $\begin{array}{l}\text { Tratamento de } \\
\text { sementes (TS) }\end{array}$ & $\mathbf{A P}$ & AIE & DC & $\mathbf{C E}$ \\
\hline Controle & $189,37 \mathrm{c}$ & $98,12 \mathrm{c}$ & $5,67 \mathrm{c}$ & $17,37 \mathrm{c}$ \\
\hline Inoculação & $209,37 \mathrm{~b}$ & $118,87 \mathrm{~b}$ & $6,33 \mathrm{~b}$ & $19,87 \mathrm{~b}$ \\
\hline Bioativação & $209,62 \mathrm{~b}$ & $117,50 \mathrm{~b}$ & $6,41 \mathrm{~b}$ & $21,87 \mathrm{ab}$ \\
\hline $\begin{array}{l}\text { Inoculação + } \\
\text { Bioativação }\end{array}$ & 244,37 a & 153,00 a & 6,97 a & 24,12 a \\
\hline Teste F & $719,98 * *$ & $466,83 * *$ & $49,89 * *$ & $49,07 * *$ \\
\hline \multicolumn{5}{|l|}{ Cobertura (C) } \\
\hline Sem N & 204,31 & 114,50 & $6,03 \mathrm{~b}$ & $19,25 \mathrm{~b}$ \\
\hline Com N & 222,06 & 129,25 & 6,61 a & $21,37 \mathrm{a}$ \\
\hline Teste F & $434,30 * *$ & $195,20 * *$ & $67,53^{* *}$ & $28,23^{* *}$ \\
\hline \multicolumn{5}{|l|}{ Interação } \\
\hline $\mathrm{TS} \times \mathrm{C}$ & $12,18^{* *}$ & $11,30 * *$ & $1,81^{\mathrm{ns}}$ & $1,92^{\mathrm{ns}}$ \\
\hline $\mathrm{CV}(\%)$ & 11,13 & 9,45 & 9,12 & 8,56 \\
\hline
\end{tabular}

Médias seguidas pela mesma letra minúscula na coluna, não diferem entre si pelo teste de Tukey a $5 \%$ de probabilidade. $\mathrm{ns}=$ não significativo. $* *=$ significativo a $5 \%$.

Tabela 5. Desdobramento da interação entre os tratamentos de sementes e a presença e ausência do nitrogênio em cobertura para o componente agronômico altura de planta $(\mathrm{cm})$ do híbrido de milho AS 1633 VT PRO3 ${ }^{\mathrm{TM}}$ conduzido na segunda safra, Pindorama, SP, 2017.

\begin{tabular}{lccc}
\hline $\begin{array}{l}\text { Tratamento de } \\
\text { sementes (TS) }\end{array}$ & Sem N & Com N & Teste F \\
Controle & \multicolumn{3}{c}{ Cobertura } \\
Inoculação & $176,34 \mathrm{Bc}$ & $202,25 \mathrm{Ac}$ & $228,50^{* *}$ \\
Bioativação & $202,42 \mathrm{Bb}$ & $216,22 \mathrm{Ab}$ & $65,15^{* *}$ \\
Inoculação + & $203,19 \mathrm{Bb}$ & $216,98 \mathrm{Ab}$ & $56,02^{* *}$ \\
Bioativação & $233,62 \mathrm{Ba}$ & $250,14 \mathrm{Aa}$ & $121,15^{* *}$ \\
\hline Teste F & $395,08^{* *}$ & $337,07^{* *}$ & \\
\hline
\end{tabular}

Médias seguidas pela mesma letra maiúscula na linha e minúscula na coluna, não diferem entre si pelo teste de Tukey a $5 \%$ de probabilidade. $* *=$ significativo a $5 \%$. 
Tabela 6. Desdobramento da interação entre os tratamentos de sementes e a presença e ausência do nitrogênio em cobertura para o componente agronômico altura de inserção da primeira espiga $(\mathrm{cm})$ do híbrido de milho AS 1633 VT PRO3 ${ }^{\mathrm{TM}}$ conduzido na segunda safra, Pindorama, SP, 2017.

\section{Tratamento de sementes(TS)}

Controle

Inoculação

Bioativação

Inoculação + Bioativação

\section{Sem N}

\section{Cobertura (C)}

Com N

110,50 Ac

126,25 Ab

$122,75 \mathrm{Ab}$

157,50 Aa
Teste F

$137,40^{* * *}$

$48,80 * *$

$24,73 * *$

$18,17 * *$

Teste $\mathrm{F}$

$129,74 \mathrm{Ba}$

179,57 **

Médias seguidas pela mesma letra maiúscula na linha e minúscula na coluna, não diferem entre si pelo teste de Tukey a $5 \%$ de probabilidade. $* *=$ significativo a $5 \%$.

Hungria (2011) relata que vários estudos conduzidos no Brasil e no exterior, têm constatado um aumento na produtividade de milho, devido à inoculação com Azospirillum, a autora salienta que estes resultados não estão correlacionados apenas com o aumento do $\mathrm{N}$, mas também com outros nutrientes como o P e o K.

Em relação ao bioativador, em sua formulação além de nutrientes também se encontram aminoácidos, os quais facilitam a absorção, pela raiz, dos nutrientes presentes no solo.

Segundo Ciampitti et al. (2011) entre os estádios V6 e V10, o potencial do número de fileiras por espiga é determinado, podendo ser afetado pelo potencial genético e pelos fatores ambientais do local, sendo reduzido se a planta for submetida a condições de estresse biótico e abiótico. Em VT o potencial de grãos por fileira na espiga é definido e o tamanho das espigas começa a ser definido, consequentemente, o potencial do número final de grãos, a partir do número de óvulos. O calor em excesso e a seca podem afetar o potencial do número de grãos.

Quanto aos componentes básicos de produção foram observadas diferenças significativas para o número de fileira de grãos, número de grãos por fileira, peso médio de 100 grãos e produtividade (Tabela 7).Garcia et al. (2008) constataram que a deficiência hídrica afeta negativamente os índices fisiológicos do crescimento na cultura do milho. Sendo que a deficiência, durante o período vegetativo, após a emissão da $12^{\mathrm{a}}$ folha, afeta ainda mais a cultura em termos fisiológicos e de produção.

$\mathrm{Na}$ Tabela 8 é possível observar o quão expressivo são os resultados de produtividade com a utilização de nitrogênio em cobertura, associado às técnicas de inoculação e bioativação, atingindo $6624,28 \mathrm{~kg} \mathrm{ha}^{-1}$ em condição de segunda safra, obtendo incremento de $2619,42 \mathrm{~kg} \mathrm{ha}^{-1}$ de produtividade de grãos. A média geral da produtividade do presente trabalho foi de $4372,98 \mathrm{~kg} \mathrm{ha}^{-1}$, estando dentro do esperado e acima da média obtida nesta segunda safra no Estado de São Paulo, que apresentou média $4189,74 \mathrm{~kg} \mathrm{ha}^{-1}$. As condições climáticas, principalmente a estiagem, foram apontadas como o grande fator responsável pelo baixo desempenho das lavouras de todo território paulista, causando forte impacto na produção total de grãos e um rendimento $27,5 \%$ inferior ao registrado na safra anterior. Duarte et al. (2017) obtiveram resultados médios de produtividade de $3872,36 \mathrm{~kg} \mathrm{ha}^{-1}$, próximo ao encontrado neste trabalho, comparando diversos híbridos, entre eles o AS 1633, o qual se destacou na competição com demais cultivares. 
Tabela 7. Componentes básicos de produção, número de fileiras de grãos na espiga (NFE), número de grãos por fileira (NGF), peso de 100 grãos (P100) em gramas e produtividade $\mathrm{em} \mathrm{kg} \mathrm{ha}^{-1}$ (PROD) do híbrido de milho AS 1633 VT PRO3 ${ }^{\mathrm{TM}}$, sob diferentes tratamentos de sementes e na presença ou ausência de nitrogênio em cobertura, conduzido na segunda safra, Pindorama, SP, 2017.

\begin{tabular}{|c|c|c|c|c|}
\hline $\begin{array}{l}\text { Tratamento de } \\
\text { sementes (TS) }\end{array}$ & NFE & NGF & P100 & PROD \\
\hline Controle & $13,17 \mathrm{c}$ & $27,67 \mathrm{c}$ & $36,07 \mathrm{c}$ & $3106,47 \mathrm{c}$ \\
\hline Inoculação & $13,70 \mathrm{~b}$ & 29,07 bc & $37,84 \mathrm{~b}$ & $4496,84 \mathrm{~b}$ \\
\hline Bioativação & $13,85 \mathrm{~b}$ & $29,77 \mathrm{~b}$ & $37,65 \mathrm{~b}$ & $4574,07 \mathrm{~b}$ \\
\hline $\begin{array}{l}\text { Inoculação + } \\
\text { Bioativação }\end{array}$ & $15,00 \mathrm{a}$ & 34,42 a & 41,52 a & 5314,57 a \\
\hline Teste F & $25,48 * *$ & $54,37 * *$ & $75,25 * *$ & $271,91 * *$ \\
\hline \multicolumn{5}{|l|}{ Cobertura (C) } \\
\hline Sem N & $13,55 \mathrm{~b}$ & $28,66 \mathrm{~b}$ & $37,68 \mathrm{~b}$ & 3473,13 \\
\hline Com N & $14,05 \mathrm{a}$ & 31,80 a & 38,86 a & 5272,84 \\
\hline Teste F & $22,25 * *$ & $62,55^{* *}$ & $19,51 * *$ & $1037,59 * *$ \\
\hline \multicolumn{5}{|l|}{ Interação } \\
\hline TS $\times$ C & $0,41^{\mathrm{ns}}$ & $2,19^{\mathrm{ns}}$ & $2,95^{\mathrm{ns}}$ & $73,61 * *$ \\
\hline $\mathrm{CV}(\%)$ & 12,17 & 13,71 & 11,96 & 7,61 \\
\hline
\end{tabular}

Médias seguidas pela mesma letra minúscula na coluna, não diferem entre si pelo teste de Tukey a $5 \%$ de probabilidade. $\mathrm{ns}=$ não significativo. $* *=$ significativo a $5 \%$

$\mathrm{Na}$ Tabela 9 estão indicados os coeficientes de correlação de Pearson das variáveis estudadas. Dessa forma, evidencia-se que todos os parâmetros estudados possui correlação positiva, de alta magnitude. As estimativas de correlação estão indicando que a produtividade está correlacionada com os principais atributos da espiga. Visto que a leitura SPAD tem sido utilizado como um parâmetro de indicativo da absorção de nitrogênio que é responsável pela capacidade fotossintetizante (CHAPMAN; BARRETO, 1997) e este pode ser utilizado com indicativo de produtividade, onde a leitura SPAD apresentou correlação positiva com a variável produtividade de grãos. Destaca-se também, as variáveis de características agronômicas, correlacionadas positivamente quanto a característica de altura da planta, em função da colheita mecanizada quanto mais alta a planta menor o grau de perdas. 
Tabela 8. Desdobramento da interação entre os tratamentos de sementes e a presença e ausência do nitrogênio em cobertura para a produtividade em $\mathrm{kg} \mathrm{ha}^{-1}$ do híbrido de milho AS 1633 VT PRO3 ${ }^{\mathrm{TM}}$ conduzido na segunda safra, Pindorama, SP, 2017.

\begin{tabular}{lcrlr}
\hline $\begin{array}{l}\text { Tratamento de } \\
\text { sementes (TS) }\end{array}$ & \multicolumn{2}{c}{ Sem N } & Teste F \\
Controle & \multicolumn{2}{c}{ Cobertura (C) } & \\
Inoculação & $2893,09 \mathrm{Bc}$ & $3319,84 \mathrm{Ac}$ & $14,58^{* *}$ \\
Bioativação & $3381,56 \mathrm{Bb}$ & $5535,13 \mathrm{Ab}$ & $398,47 * *$ \\
Inoculação + & $3613,01 \mathrm{Bb}$ & $5612,13 \mathrm{Ab}$ & $295,88^{* *}$ \\
Bioativação & $4004,86 \mathrm{Ba}$ & $6624,28 \mathrm{Aa}$ & $549,50 * *$ \\
Teste F & $34,55^{* *}$ & $310,98 * *$ & \\
\hline
\end{tabular}

Médias seguidas pela mesma letra maiúscula na linha e minúscula na coluna, não diferem entre si pelo teste de Tukey a $5 \%$ de probabilidade. $n s=$ não significativo. $* *$ = significativo a $5 \%$.

Tabela 9. Correlação de Pearson entre os parâmetros avaliados no experimento envolvendo a cultura do milho de segunda safra, Pindorama, SP, 2017.

\begin{tabular}{|c|c|c|c|c|c|c|c|c|c|c|}
\hline & $\begin{array}{c}\text { SPAD } \\
\text { V3 }\end{array}$ & $\begin{array}{c}\text { SPAD } \\
\text { V6 }\end{array}$ & $\begin{array}{c}\text { SPAD } \\
\text { E }\end{array}$ & $\mathbf{A P}$ & AIE & DC & CE & NFG & NGF & P100 \\
\hline SPAD V6 & $0,91 * *$ & - & - & - & - & - & - & - & - & - \\
\hline SPAD E & $0,92 * *$ & $0,92 * *$ & - & - & - & - & - & - & - & - \\
\hline AP & $0,95 * *$ & $0,96 * *$ & $0,92 * *$ & - & - & - & - & - & - & - \\
\hline AIE & $0,94 * *$ & $0,93 * *$ & $0,91 * *$ & $0,98 * *$ & - & - & - & - & - & - \\
\hline $\mathrm{DC}$ & $0,88 * *$ & $0,83 * *$ & $0,89 * *$ & $0,87 * *$ & $0,84 * *$ & - & - & - & - & - \\
\hline $\mathrm{CE}$ & $0,89 * *$ & $0,90 * *$ & $0,84 * *$ & $0,92 * *$ & $0,93 * *$ & $0,78 * *$ & - & - & - & - \\
\hline NFG & $0,86^{* *}$ & $0,84 * *$ & $0,86^{* *}$ & $0,85 * *$ & $0,84 * *$ & $0,83 * *$ & $0,78 * *$ & - & - & - \\
\hline NGF & $0,89 * *$ & $0,83^{* *}$ & $0,81 * *$ & $0,89 * *$ & $0,89 * *$ & $0,79 * *$ & $0,86^{* *}$ & $0,84 * *$ & - & - \\
\hline P100 & $0,86^{* * *}$ & $0,92 * *$ & $0,85^{* *}$ & $0,92 * *$ & $0,90 * *$ & $0,77 * *$ & $0,84 * *$ & $0,76 * *$ & $0,82 * *$ & - \\
\hline PROD & $0,83 * *$ & $0,77 * *$ & $0,80 * *$ & $0,77 * *$ & $0,71 * *$ & $0,83 * *$ & $0,71 * *$ & $0,78 * *$ & $0,76 * *$ & $0,68 * *$ \\
\hline
\end{tabular}

$* *$ = significativo a $5 \%$.

\section{CONCLUSÃO}

A combinação dos tratamentos de sementes "inoculação + bioativação", propicia melhores resultados no crescimento/desenvolvimento da planta e na produtividade, do híbrido de milho AS 1633 VT PRO3 ${ }^{\mathrm{TM}}$, de segunda safra, quando em comparação com a aplicação dos referidos tratamentos de sementes, aplicados separadamente. 


\section{REFERÊNCIAS}

ARGENTA, G. Monitoramento do nível de nitrogênio na planta como indicador da adubação nitrogenada em milho. 2001. 112 f. Tese (Doutorado) - Universidade Federal do Rio Grande do Sul, Porto Alegre, 2001.

CANTARELLA, H.; DUARTE, A. P. Manejo da fertilidade do solo para a cultura do milho. In: GALVÃO, J. C. C.; MIRANDA, G. V. (Eds.) Tecnologia de produção de milho. Viçosa: UFV, 2004. p. 139-182.

CASTRO, P. R. C.; KLUGE, R. A.; PERES, L. E. P. Manual de Fisiologia Vegetal: teoria e prática. Piracicaba: Editora Agronômica Ceres, 2005. 650p.

CHAPMAN, S. C.; BARRETO, H. J. Using a chlorophyll meter to estimate specific leaf nitrogen of tropical maize during vegetative growth. Agronomy Journal, vol. 89, pag. 557-562, 1997.

CIAMPITTI, I. A.; ELMORE, R. W.; LAUER, J. How a corn plant develops. Iowa: State University Extension, 2011.

CONAB. Companhia Nacional de Abastecimento. Acompanhamento da safra brasileira: grãos. Milho segunda safra. Brasília, v. 6, n. 2, p. 18-17, Agosto. 2017.

DUARTE, A. P. Milho safrinha se consagra e caracteriza um sistema peculiar de produção. Visão agrícola, n. 13, 2015. Disponível em:

https://www.esalq.usp.br/visaoagricola/sites/default/files/VA_13_Manejo_cultura-artigo4.pdf. Acesso em: 27 de maio de 2019.

DUARTE, A. P. et al. Avaliação de cultivares de Milho Safrinha Transgênico na Região Norte/Noroeste do Estado de São Paulo em 2017. In XIV SEMINÁRIO NACIONAL DE MILHO SAFRINHA, 2017. CUIABA-MT, 2017. Anais... (CD) Embrapa, Brasília, DF, 2013.

EMPRESA BRASILEIRA DE PESQUISA AGROPECUÁRIA. Sistema brasileiro de classificação de solos. 3. ed. Brasília, DF, 2013. 353 p.

EMPRESA BRASILEIRA DE PESQUISA AGROPECUÁRIA. Sistema de produção do milho. Embrapa Milho e Sorgo. 7 ed. Set, 2011. Disponível em:

<http://www.cnpms.embrapa.br/publicacoes/milho_7_ed/feraduba.htm_. Acesso em: 17 nov. 2017.

FANCELLI, A. L.; DOURADO NETO, D. Produção de milho. Guaíba: Agropecuária, 2000. 360 p.

FERREIRA, L. A.et al. Bioestimulante e fertilizante associados ao tratamento de sementes de Milho. Revista Brasileira de Sementes, v.29, n.2, p.80-89, 2007.

GARCIA, A.et al. Análise de crescimento de uma cultura de milho submetida a diferentes regimes hídricos. Nucleus, v. 5. n. 1 , mar. 2008.

GUIMARÃES, P. S. Desempenho de híbridos simples de milho (Zea mays L.) e correlação entre heterose e divergência genética entre as linhagens parentais. 2007. 111 p. Dissertação (Mestrado) Instituto Agronômico, Campinas, 2007.

HUERGO, L. F.et al. Regulation of nitrogen fixation in Azospirillum brasilense. In: CASSÁN, F. D.; SALAMONE, I. G. Azospirillum sp.: cell physiology, plant interactions and agronomic research in Argentina. Córdoba, Asociación Argentina de Microbiología, p. 17-28, 2008.

HUNGRIA M.et al.O. Inoculation with selected strains of Azospirillum brasilense and A. lipoferum improves yields of maize and wheat in Brazil. Plant and Soil, v. 331, p. 413-425, 2010. 
HUNGRIA, M. Inoculação com Azospirillum brasiliense: inovação em rendimento a baixo custo. Londrina: Embrapa Soja, 2011. 36p.

HUNGRIA, M.; NOGUEIRA, M.; ARAUJO, R. S. Soybean seed co-inoculation with Bradyrhizobium spp. and Azospirillum brasilense: a new biotechnological tool to improve yeld and sustainability. American Journal of Plant Sciences, Irvine, v. 6, p. 811-817, 2015.

LARCHER, W. Ecofisiologia Vegetal. São Carlos: Rima, 2004. 531p.

MARQUARD, R. D. E TIPTON, J.L. Relationship between extractable chlorophyll anda na in situ method to estimate leaf grenness. Horticulture Science. p.22-27, 1987.

MOLL, R. H.; JACKSON, W. A.; MIKKELSEN, R. L. Recurrent selection for maize grain yield: Dry matter and nitrogen accumulation and partitioning changes. Crop Science, v. 34, p. 874- 881, 1994.

MOREIRA, F. M. S.; SIQUEIRA, J. O. Microbiologia e bioquímica do solo. 2. ed. Lavras: Editora UFLA, 2006, p. 729.

RAIJ, B. van et al. Recomendações de adubação e calagem para o Estado de São Paulo. 2. ed. Campinas: IAC, 1997, p. 285.

RAJCAN, I. E TOLLENAAR, M. Source:sink ratio and leaf senescence in maize: II. Nitrogen metabolism during grain filling. Field Crops Research, v. 60, p. 255-265, 1999.

TAIZ, L.; ZEIGER, E. Fisiologia Vegetal. 3. ed. Porto Alegre: Artmed, 2004. 719p.

VICTORIA, R. L.; PICCOLO, M. C.; VARGAS, A. A. T. O ciclo do nitrogênio. In: CARDOSO, E. J. B. N.; TSAI, S. M.; NEVES, M. C. P. Microbiologia do solo. Campinas, Sociedade Brasileira de Ciência do Solo, 1992. p. 105-120. 